\title{
Antoni Rosner, the first associate professor of dermatology and venereology in Poland
}

\author{
Dariusz Staszek, Czesław Jeśman
}

History of Science and Military Medicine Department, Medical University of Lodz, Poland Head of Department: Czesław Jeśman Prof. MUL, PhD, MD

Postep Derm Alergol 2014; XXXI, 2: 98-103

DOI: $10.5114 /$ pdia.2014.40928

\begin{abstract}
The article presents an outline of the development of world and Polish dermatology. The author points out to the first descriptions of skin diseases by ancient and medieval medical luminaries. The outline of the Polish dermatology is based on examples of doctors living in the $16^{\text {th }}$ and $17^{\text {th }}$ centuries. The first clinics of skin and venereal diseases in Poland appeared, like in other European countries, in the second half of the $19^{\text {th }}$ century. Antoni Rosner, the first associate professor of clinical studies, greatly contributed to the development of this medical field. The description of his life and work is the background for the presentation of opening and developing the clinic of skin and venereal diseases in Krakow as well as the presentation of university curriculum at the Faculty of Medicine of the Jagiellonian University.
\end{abstract}

Key words: Antoni Rosner, dermatology.

\section{Introduction}

In 2012, we celebrated the one hundred and fiftieth anniversary of the first habilitation in dermatology and venereology in Poland. This event is an occasion for presenting the biography of Antoni Rosner, the first associate professor of dermatology at the Jagiellonian University, and also events related to the opening of a dermatological clinic. Antoni Rosner was born in Tarnów. He studied philosophy and medicine in Vienna and worked in a famous clinic run by professor Ferdinand von Hebra. In 1862, he defended his habilitation thesis in dermatology at the Jagiellonian University and opened of a dermatological clinic. In poor housing conditions he focused on teaching and attracted doctors who treated skin diseases. He educated e.g. Władysław Reiss and Aleksander Zarewicz, who then were professors of the Jagiellonian University.

\section{Outline of the development of dermatology}

In 2012, we celebrated the one hundred and fiftieth anniversary of the first habilitation in dermatology and venereology in Poland. This is an occasion for presenting the biography of Antoni Rosner, the first associate professor of dermatology at the Jagiellonian University, and also events related to the opening of a dermatological clinic.
Skin diseases are as old as the humankind. However, dermatology and venereology have been separate medical sciences for a relatively short period of time. It can be said that dermatology has existed for long but its history is short.

The ancient Indian Vedas, old Hebrew manuscripts, works of Hippocrates, Galen and Celsus are the earliest sources of information on skin diseases. In ancient countries, skin and venereal diseases were a common problem which resulted from great urban development, lack of knowledge of hygiene and lack of hospitals. Thus, there was a vivid interest in dermatology and venereology at those times. Although skin and venereal diseases were described as early as in ancient times, sources of modern dermatology and venereology should be sought much later, mainly in medicine of internal diseases and also in surgical medicine. Dermatology started to be a separate medical science only in the $18^{\text {th }}$ and $19^{\text {th }}$ centuries.

The aetiology and methods of treating skin diseases allow us to identify four stages in the development of dermatology: the first - based on the humoral theory of Hippocrates, second - on basics of morphology, third on pathological anatomy, and fourth stage is a biological one [1].

The first stage was the longest and lasted until the $18^{\text {th }}$ century. It was based mainly on the humoral theory

Address for correspondence: Czesław Jeśman Prof. MUL, PhD, MD, History of Science and Military Medicine Department, Medical University of Lodz, 7/9 Żeligowskiego St, 90-643 Lodz, Poland, phone: +48 42639 32 70, e-mail: czeslaw.jesman@umed.lodz.pl Received: 25.02.2013, accepted: 8.09.2013. 
as doctors adopted that skin diseases appear as a result of accumulation of body fluids. At that time, empiricists were also very active and they emphasized the importance of the treatment process. For four hundred years empiricists introduced and effectively treated skin diseases with sulphur [2, 3]. In this period, Hieronymus Mercurialis wrote the first manual book on dermatology (the $16^{\text {th }}$ century) [4].

In the second stage of the development of dermatology, doctors made classifications of dermatological lesions on the basis of morphological changes. French medical doctors, Anne Charles Lorry and Jean Louis Alibert, as well as Joseph Jacob Plenck from Vienna and Robert Willan from England represent the second stage. In 1808, Robert Willan published a handbook On cutaneous diseases and discovered and described psoriasis. He was the founder of the school of English dermatology and together with Jean Louis Alibert - a pioneer in dermatological iconography $[5,6]$.

The third stage of the development of dermatology was observed in the second half of the $19^{\text {th }}$ century and was the beginning of modern dermatology. Doctors used their knowledge of pathological anatomy [2]. Ferdinand von Hebra is closely connected with this period. This outstanding dermatologist from Vienna made a classification of skin diseases and identified their clinical characteristics on the basis of pathological anatomy [7]. He worked in the ward run by Joseph Skoda. By treating patients with skin lesions he gained a lot of experience (10,000 cases). He defended his habilitation thesis in 1845, which was a breakthrough in treating dermatology and venereology as separate medical specializations. In 1849, he became the first professor of dermatology in Vienna [3, 8]. He created a modern school of dermatology. It became very famous and was visited by many dermatologists from around the world. The school used eyesight and memory stimuli, which initiated the development of descriptive dermatology. This, in turn, made it possible to identify many varieties of diseases. Ferdinand von Hebra's followers also contributed to further development of Vienna dermatology. His followers in Vienna were Moritz Kaposi, Heinrich Auspitz and Isidor Neumann [2, 6, 9].

The last stage of dermatology started thanks to the development of bacteriology and histopathology. Paul Gerson Unna, a German dermatologist, is the most prominent representative of this stage. He came from a medical family and opened his famous histopathology laboratory in Hamburg. He invented and improved new techniques used in histopathology and dermatological treatment. Starting from 1888, he organized and ran theoretical and practical courses on histopathology in his laboratory. He shared his knowledge with many German and foreign doctors who visited him. One of his students was Franciszek Krzyształowicz, who later was a professor and the head of dermatological clinics in Krakow and Warsaw $[2,10]$.

\section{Outline of the development of dermatology in Poland}

The Polish and European dermatology and venereology developed simultaneously. It was connected with a spread of venereal diseases, general development of medical sciences and opening of first research centres. We can find a lot of details of skin and venereal diseases in the $16^{\text {th }}$ century works by Maciej of Miechów, Jan Benedict Solfa, Marcin of Urzędów or Sebastian Petrycy. Maciej of Miechów was a professor of the Krakow University. In 1495, he announced an outbreak of syphilis in Krakow $[8,11]$. Attempts to treat skin and venereal diseases were made as early as in the $16^{\text {th }}$ century. In 1528 , in Saint Sebastian meadows, outside the city walls, the Saint Roch Hospital was opened. It consisted of six wooden houses, and in three of them doctors treated venereal diseases. One of the treatment methods included rubbing in mercury ointment. After this procedure, patients were put in heated furnaces [12].

Doctors from the Holy Spirit Hospital, located in Krakow, hardly ever agreed to admit patients with venereal diseases. They followed this strict policy until the $19^{\text {th }}$ century. As late as in 1821, in the hospital (founded in 1231) a ward for venereal patients was opened. The patients were moved from the Saint Roch Hospital. This new ward was later converted into a dermatological clinic [13].

When dermatology was not a separate specialization and when there were no dermatological clinics, surgeons both in Poland and other European medical universities were responsible for teaching dermatology and venereology. It was a common practice for surgeons as venereal diseases were spreading rapidly and syphilitic processes destroyed soft tissues and bones. Then, such disorders required surgical interventions [14].

The first dermatological clinic in Poland was opened in the second half of the $19^{\text {th }}$ century. This period is characterized by reforms and bringing the Jagiellonian University, the second greatest university in Central Europe, to its former glory. Józef Dietl, a distinguished doctor, scientist, reformer and finally the mayor of the City of Krakow contributed to the development of dermatology in Poland. He was the University Rector only for 1 year, i.e. in the academic year 1861/1862. Then, the Ministry of State of Austria did not allow for his nomination any longer. However, he managed to introduce the Polish language in the university, a habilitation system and opened new departments at the Faculty of Medicine. At that time, Antoni Rosner was habilitated and became the first associate professor of the Jagiellonian University [5, 15].

\section{The activity of Antoni Rosner}

Antoni Rosner was born on 9 November 1831 in Tarnów and in 1847, he graduated from the secondary school. He came from a Jewish family. His father David was a surgeon. He had three brothers. Two were doctors 
and one - an Austrian officer. After Antoni completed his secondary education he went away to Vienna to study philosophy and medicine. He finished his studies in 1853. In 1854, he passed his initial medical exam and was employed as a trainee in the Ward of Internal Medicine, run by professor T. Helm in the Vienna General Hospital. In May 1855, he received a degree of medical doctor. Between October 1855 and May 1857, he worked in Hungary as a family doctor for Count Zichy and in 1856, he passed an exam in Vienna and received his Master's degree in obstetrics. After coming back to Vienna he continued his work in the Vienna General Hospital. At first, as an assisting doctor in a clinic run by professor Hebra. He was employed in the Ward of Skin Diseases. In April 1858, he asked to be transferred to the Clinic of Internal Diseases run by professor Sigmund. After a year of work in the Surgical Ward and the Ward of Female Diseases run by K. Urlich he received a scholarship from the Ministry of Enlightenment for doctors specializing in surgery in the clinic of professor Dumreicher. He completed his 2-year course, passed an exam and received a diploma in surgery. From September 1862, he worked in the clinic of professor Hebra. He dealt with many patients and treated only skin diseases $[16,17]$.

On 26 January 1862, when he was still in Vienna, he asked the authorities of the Faculty of Medicine at the Jagiellonian University to give him a post of an associate professor in the field of dermatological and venereal diseases. In the opening part of his request he quotes the words of the Rector of the Jagiellonian University put in the "Czas" newspaper, in which he suggested applying for positions of associate professors. The application was enclosed with his treaty "Chancre and syphilitic disease" and positive opinions written by his Vienna professors: F. Hebra, K. Urlich, J. Dumreicher, K. Sigmund and T. Helm. Antoni Rosner also proposed some lectures he wanted to give after he would be granted the post. He had an idea of introducing 2- or 3-month courses, $5 \mathrm{~h}$ per week, on skin and venereal diseases. Three hours were to be meant for teaching skin diseases and two - for venereal diseases. In his teaching methods he wanted to make his students become self-learners and make them draw their own conclusions and gain enough experience to be later on able to identify skin and venereal diseases. He wanted to devote a lot of time to methods of treatment of these diseases as he believed that successful treatment very often results from proper implementation of particular methods $[17,18]$. The habilitation procedure was discussed during sessions of the Faculty of Medicine at the Jagiellonian University, held on 12 February, 17 March and 26 March. Finally, he was habilitated on 29 March 1862. The habilitation thesis was approved by the Committee of the Faculty of Medicine. In the opinion of the committee members, the knowledge was presented in a clear and concise manner and the author proved to be able to identify and explain doubts on his own. Two days lat- er, the Dean of the Faculty of Medicine, doctor Fryderyk Skobel, asked the Senate of the Jagiellonian University to send Rosner's habilitation to the ministry. In May 1862, the position of the associate professor for Rosner was officially approved by the authorities in Vienna $[8,19]$.

On 23 July 1862, Rosner, an associate professor, applied in writing to the Senate of the Jagiellonian University to allow him to give lectures on skin and venereal diseases. He believed that it was his duty to start as soon as possible, that is already in October. He also claimed that even the best lectures, but not accompanied by clinical practice, would turn out ineffective. Thus, he asked to allow his students to visit patients in any of Krakow hospitals [20]. His request was accepted and in the winter semester of the academic year 1862/1862, he started his lectures in the Holy Spirit Hospital. He taught $5 \mathrm{~h}$ a week, between 2 and 3 o'clock in the afternoon [21]. The lectures involved presentations of medical cases from the military hospital. However, in February 1863, the lectures were called off, which was a consequence of the protest of Sisters of the Order of Mercy looking after patients in the Holy Spirit Hospital [20]. In March 1863, the Mother Superior of the order was against opening a clinic in the ward for syphilitic patients [22]. The financial aspect became an argument against Rosner and his lectures. The sisters also claimed that using female patients in the lectures is immoral. Rosner asked the Faculty of Medicine to solve the dispute [20]. Despite the problems, Rosner decided to continue his lectures. He moved from the lecture hall in the Holy Spirit Hospital to professor Dietl's clinical hall. The lectures were however only theoretical. He was supported in his attempts by the Faculty of Medicine. Finally, on 8 July 1863, he managed to open 2 patient rooms and one room for medical examinations in the Ward of Skin and Venereal Diseases in the Holy Spirit Hospital. These two rooms, with 20 beds for men and women, and the examination room were later turned into the Krakow dermatological clinic [8]. The ministry issued a document in which the authorities agreed to the lectures on skin and venereal diseases. However, they set forth certain conditions, too. Students were allowed to enter particular rooms and forbidden to enter other rooms. Moreover, they were allowed to visit the hospital only during lecture hours. With regard to the patients, students were allowed to use patients as "clinical material" only when patients agreed and they could not be forced to be admitted to clinical rooms. The patients had to be treated and fed in compliance with procedures adopted in the Holy Spirit Hospital [22]. In October, professor Rosner started to give $5 \mathrm{~h}$ of lectures per week. In the winter semester, the lectures were on exanthemas and venereal diseases and in the summer semester - on skin and venereal diseases, which were accompanied by practical classes in the clinic [21]. One hundred and twenty four students attended the lectures at that time [23]. There were 187 patients treated in the clinic, which 
still worked informally at that time. A similar number of patients came for outpatient consultations. At the beginning, the clinic did not have basic equipment. Rosner was not given any remuneration for his work and often bought the most needed things with his own money [8, 23]. In 1864, the clinic was equipped with a wooden cabinet with shelves, thirty wooden stools, a chair for examining women, two sinks, a device for cold injections, four porcelain hysteroscopes, a tourniquet and a device for urine analysis [24]. Most of the equipment was bought with Rosner's financial resources. Later on, he also paid for a bathtub for sitz baths and a urinal for storing urine. Attempts made by the Faculty of Medicine and Rosner himself appeared to be successful. At the beginning of the academic year 1867/1868, he was appointed a voluntary university professor with an annual remuneration of 500 zlotys [20].

The authorities of the University Senate many times applied to the Austrian government to open a new department and clinic. They were however refused. In the rescript issued on 9 September 1870, the Austrian authorities confirmed that the Jagiellonian University meets basic requirements but they decided not to allow a separate department of skin and venereal diseases to be opened. They called the Senate to present further explanations with regard to proper equipment of the clinic and its supervision (the head of the clinic was appointed by the university authorities but the clinic was to be formed from the Ward of Skin Diseases of Holy Spirit Hospital, whose primarius doctor reported to the head of the hospital) [20, 25].

Finally, on 11 March 1871, the government in Lvov officially declared that under the Resolution, as of 31 January 1871 they allow a separate department of skin and venereal diseases to be opened at the Faculty of Medicine of the Jagiellonian University and a clinic for this department. Professor Rosner was appointed the head of the department. Starting on 1 May 1871, he was going to be given an annual salary of 1200 zlotys by the Krakow Scientific Fund. The Clinic of Skin and Venereal Diseases, formed from the hospital ward, was to remain within the Holy Spirit Hospital. Rosner was to work as a voluntary ward doctor and report to the head of the hospital. He was told to treat patients of the clinic and the hospital according to procedures adopted by other doctors. Moreover, the clinic received one-time financial grant of 200 zlotys for its basic needs and an annual grant of 60 zlotys to ensure proper functioning of the clinic. It was also possible to employ an assistant [20, 21, 25].

The official opening of the Clinic of Skin and Venereal Diseases did not contribute to the improvement of relationships between Rosner and the Sisters of Mercy. Many times they demanded Rosner to pay the cost of running the clinic. The demands were presented in writing. In a letter of 1872 between the University Senate and the Faculty of Medicine on the ways of running the clinic, the sisters demanded 1304 zlotys from the Scientific
Fund to pay the costs of treating patients in 1869-1871. The sisters accused Rosner of prescribing the patients wrong diets and feeding them with the wine soup too often. The sisters complained about increased expenses of treating the patients, especially about an increased use of ointment and changing bed linen too often. Finally, after many clarifications provided by Rosner, the sisters' complaints were found unjustified [20].

Another problem that Rosner had to face up to was connected with the patients' refusal to be "clinical material". They did not want to be shown during classes. The patients did not have any benefits from the stay in the clinic and they chose the neighbouring ward. Thus, Rosner constantly asked for financial support to cover the cost of food and treatment, which was higher than in other wards. In 1869-1871, 356 patients were treated in the clinic. On average, they stayed for 40 days. In this period, 12 patients were admitted because of scabies, most of them with complications, i.e. a rash. The average stay for scabies patients was 6 days. In 5 most severe cases, the doctor applied Wilkinson's ointment and in less severe cases - Peruvian balm [20].

On 19 April 1879, both the Clinic of Skin and Venereal Diseases and the neighbouring Ward of Skin and Venereal Diseases were moved to the Saint Lazarus Hospital. The change did not improve housing conditions. In his report, professor Rosner wrote: "The Clinic of Skin and Venereal Diseases, which moved to the Saint Lazarus Hospital on 19 April 1879, consists now of (a) a lecture hall and (b) four toilets for patients, i.e. two toilets for 10 male patients and two toilets for 10 female patients. The lecture hall is smaller than the one in the Holy Spirit Hospital and it serves many purposes. It is a place for giving lectures, a changing room for clinical patients and those coming for consultations, it is used for storing clinical equipment, as a toilet for examined female patients and finally as the professor's office and a chemical laboratory. The patients' toilets are also smaller than those in Holy Spirit Hospital..." [20].

A small number of clinical beds resulted in a small number of patients who could be used during lecture demonstrations. Professor Rosner tried to open another ward which would have 30 beds -15 for women and 15 for men. In his opinion, that number might have allowed for proper functioning of the clinic. He also looked for financial support and tried to open a bigger lecture hall [20].

In autumn 1893, the Surgical Ward, so far located in the Saint Lazarus Hospital, was moved to a new building. Thanks to efforts made by the College of Professors of the Faculty of Medicine, some empty rooms were adapted to the needs of the Clinic of Skin and Venereal Diseases. The number of beds increased to 30. Moreover, the clinic had now a bigger lecture hall and a room for outpatients. The Ministry of Denominations and Enlightenment agreed to cover the cost of opening of the outpatient clinic [20]. 
Under the Rescript of 31 October 1894, the clinic was allowed to treat patients in compliance with proper clinical requirements. That long-awaited change was to be introduced at the beginning of the academic year $1894 / 1895$. Any excessive expenses were to be paid by the state [20]. However, the clinic was only allowed to provide its patients with more and better quality food as well as to prescribe them more expensive medicaments. It was difficult to get financial resources for other things. The way of financing the clinic was much more complicated than in the case of standard hospitals. Primarius doctors from other wards were allowed to apply for grants up to 60 crowns, and the money could be spent on urgent needs. The procedure of granting money to the clinic was much more complicated and it took more time. Very often doctors of the clinic could not receive financial grants for medical care, treatment or prophylaxis because the application turned out to be outdated. The patient had left the clinic before the clinic received approval from the authorities. The clinic faced up to similar problems when it came to its didactic activity. As a result of many delays, clinics in the Saint Lazarus Hospital were worse equipped than any others [20].

It was difficult to conduct scientific research in such poor housing and financial conditions. Thus, Rosner focused on teaching. He gave lectures from 1862, at first - $5 \mathrm{~h}$ a week. From 1872 on, there were $6 \mathrm{~h}$ a week, still between 2 and 3 o'clock in the afternoon. From Monday to Wednesday he lectured on venereal diseases and from Thursday to Saturday - skin diseases [21].

In the introductory part of his lectures, Rosner mentioned the outstanding F. Hebra from Vienna, who pointed out to the importance of dermatology. He shared Hebra's opinion and claimed that skin diseases are not different from internal diseases and they can result from hyperaemia, ischaemia, extravasation, neoplasms and inflammation. Rosner emphasized the importance of proper examination of the patient. He claimed that the whole body of the patient should be examined if possible. He pointed out that some lesions might be unnoticed, but decisive for setting the proper diagnosis. He gave an example of different lesions in the course of scabies and prurigo. In the latter disorder, a patient's skin is covered with slight nodules and the "grooves" are a bit deeper. He also stressed the importance of proper light. In his opinion, a doctor can identify skin lesions in electric or natural light more easily than in gas or candle light. Gas and candle light makes it impossible to evaluate the skin colour and potential changes. Rosner started examining his patients by making a general skin evaluation. He identified its colour, glow, thickness and moisture level. He assessed hair and only then he tried to detect any lesions [26].

Professor Rosner divided skin diseases into two groups, i.e. those which affect a certain skin area and those which are symptoms of other systemic diseases.
In his lectures he followed the anatomical and clinical division introduced by Hebra. On the basis of anatomical changes, he divided them into 12 parts [26].

In his lectures professor Rosner claimed that skin diseases are not only caused by harmful external factors. An acute skin rash in the course of blood infection was compared to a syphilitic rash - "a syphilitic element" circulating in the blood is accumulated in the skin. He believed that skin disorders such as acne rosacea, pemphigus or urticaria are a result of changes in the function of female reproductive organs. He admitted that it was difficult to identify a relationship between lesions and their causes. Pemphigus is explained with the reflex theory, according to which the irritated uterus causes some vasomotor changes in the skin. A rash which appears after eating wild strawberries results from an inflammation, which in turn, was induced by irritating tongue nerve endings. The irritated endings brought about the irritation of the central part of the vasomotor organ. The professor pointed out to the importance of the central and peripheral nervous system by giving an example of herpes zoster. He claimed that food and medicines contributed to the aetiology of skin diseases. Apart from wild strawberries he mentioned lobsters, oysters, and also bromine, arsenic trioxide, quinine and opium. He believed that not all cases could be explained with "a reflex change". A persistent rash was not a consequence of "the reflex" but accumulation of some substances in the blood, which caused skin lesions [26].

When analyzing the aetiology of diseases he mentioned food, care and hygiene. He claimed that the occurrence of different skin disorders depend on different geographical and climatic zones. Prurigo is a common disease in Poland but it hardly ever occurs in England. Psoriasis is common in England but not in Poland. He stressed frequent cases of leprosy in Norway. With regard to psoriasis and ichthyosis, he emphasized the importance of hereditary factors. Also external factors, such as scalds or frostbites might contribute to skin diseases. Finally, he mentioned parasites: plant (fungi) and animal [26]

Professor Rosner must have had a comprehensive and extensive medical knowledge because he became the head of the Medical Clinic. After the death of professor Karol Gilewski there were some personal problems. An extending procedure of appointing heads led to some temporary changes. Alfred Biesiadecki, a professor of pathological anatomy at the Jagiellonian University, was at first the head of the Medical Clinic [27, 28]. Under the Resolution of the Faculty of Medicine of 20 March 1874, Antoni Rosner immediately replaced Alfred Biesiadecki and in the summer and winter semesters he gave lectures on pathology and special medical therapy. At the same time he started to be responsible for the clinic equipment, i.e. 24 beds. He exercised his duties for a year. In 1875, professor Edward Korczyński became the head of the Medical Clinic [21, 28]. 
Moreover, in 1895, Rosner was the Dean and in 1896 , the Vice-Dean of the Faculty of Medicine at the Jagiellonian University [29].

During his work at the Jagiellonian University, Rosner enjoyed good health. Only on the day he died, i.e. on 25 August 1896, he complained of a heart pain. He made his name famous as he was always willing to bring relief to patients. He was also recognized as a great teacher of young doctors. "He was highly respected as the Head of the Medical Clinic and as a doctor. He gave his love to anybody who had an occasion to become his friend. In his everyday practice he truly cared about patients. Not only was he their advisor but also companion. They really trusted him (...). Apart from being a devoted medical professional he was vividly interested in political and social issues. He was deeply interested in everything that was connected with his city, country and nation. Thanks to his character he was a respectable person". He was married with seven children. Of three sons; Ignacy was the Vice-Secretary of the Council of Ministers in Vienna, Feliks was an auscultator in the court and Alexander - an associate professor of obstetrics at the Jagiellonian University. He could not improve the difficult housing conditions so he concentrated on teaching. He was not only an outstanding doctor but also a great teacher. He attracted doctors who dealt with treating skin diseases. He educated Władysław Reiss and Aleksander Zarewicz, who later on became professors and also the distinguished doctors - Henryk Sokołowski and Ferdinand Obtułowicz were his students [29].

We will remember professor Rosner as the first professor of dermatology in Poland. He was buried in the Rakowicki Cemetery (section VIII, the southern-western corner).

\section{Conflict of interest}

All authors declare no conflict of interest.
7. Gutowski W. Polish dermatology and venereology at the turn of the nineteenth and the twentieth centuries [Polish]. Archiwum Historii Medycyny 1971; XXXIV: 425-9.

8. Lejman K. An outline of the history of Dermatology Department at the Jagiellonian University and the Academy of Medicine in Cracow. Chapter of the work: Medical Science at the 600th anniversary of the Jagiellonian University [Polish]. Państwowe Wydawnictwo Naukowe, Krakow 1964; 447-70.

9. Romiti N. The pioneers of dermatology - Part 1: the life and works of Ferdinand von Hebra. An Bras Dermatol 2004; 79: 733-5.

10. Romiti N. The pioneers of dermatology - Part 2: the life and works of Paul Gerson Unna. An Bras Dermatol 2005; 80: 89-90.

11. Walter F. Study of venereal diseases [Polish]. Krakow 1934.

12. Wachholz L. Cracow's hospitals [Polish]. 1921.

13. Lejman K. An outline of the history of syphilis [Polish]. Archiwum Historii Medycyny 1969; XXXII: 125-45.

14. Lejman K. The achievements of the famous Polish nineteenth century surgeons in the field of venereology [Polish]. Przegl Dermatol 1968; 55: 621-9.

15. Tempka T. Six cenuries of medicine in Krakow [Polish]. Volume I. CVs. Józef Dietl., Krakow 1963; 79-111.

16. Polish Biographical Dictionary. Vol XXXII, 105-106 (Piotr Szarejko).

17. Jagiellonian University Archives, WL II 133 Rosner Antoni.

18. Czas, No 251, Kraków, 31st October 1861 www.mbc.malopolska.pl.

19. Jagiellonian University Archives, S II 582.

20. Jagiellonian University Archives, WL II 174.

21. Jagiellonian University Archives, L 27/3.

22. ASMK AD 158

23. Gołębiowska I. The history of the Dermatological Clinic of Jagiellonian University (1862-1918) [Polish]. Archiwum Historii Medycyny, Warsaw 1958; XXI: 79-120.

24. University Departments in Krakow. Krakow 1864.

25. Jagiellonian University Archives S II 827.

26. Rosner A. Lectures on skin diseases during six-month summer time [Polish]. Krakow 1890.

27. Jagiellonian University Archives S II 619, Biesiadecki Alfred.

28. Jagiellonian University Archives WL II 164.

29. Czas No. 196, Krakow 27th August 1896; www.mbc.malopolska.pl

\section{References}

1. Straszyński A. An outline of the history of dermatology with a special emphasis on the development of dermatology in Poland [Polish]. Poznań 1939.

2. Straszyński A. An outline of dermatology [Polish]. PZWL, Warsaw 1951

3. Szumowski W. History of medicine in philosophical terms [Polish]. Wydawnictwo Marek Derewiecki, Kęty 2008.

4. Seyda B. History of medicine at a glance, part II (from the mid-seventeenth to the mid-twentieth century) [Polish]. PZWL, Warsaw 1965.

5. Lejman K. Polish dermatology and venereology during the century period preceding the establishment of the first university departments of this specialty in our country. The diary of XVI Congress of the Polish Society of Dermatology [Polish]. Przegl Dermatol 1961; Suppl.: 463-555.

6. Iwan H. McCaw A. Synopsis of the history of dermatology. Ulster Med J 1944; 13: 109-22. 